\title{
DAMATTA E RIBEIRO: SEMELHANÇAS E DIFERENÇAS NA TRADUÇÃO PARA O INGLÊS DE TERMOS E EXPRESSÕES DA SUBÁREA DE ANTROPOLOGIA NAS OBRAS CARNAVAIS, MALANDROS E HERÓIS E O POVO BRASILEIRO
}

\author{
Talita Serpa* \\ Universidade Estadual Paulista "Júlio de Mesquita Filho" \\ Diva Cardoso de Camargo** \\ Universidade Estadual Paulista "Júlio de Mesquita Filho"
}

\begin{abstract}
Resumo: Este estudo analisa o processo tradutório para o inglês de termos e expressões presentes em duas obras dos antropólogos Roberto DaMatta e Darcy Ribeiro e nas respectivas traduções. Para tanto, fundamentamo-nos nos Estudos da Tradução Baseados em Corpus (BAKER, 1995, 1996, 2000; CAMARGO, 2007), na Linguística de Corpus (BERBER SARDINHA, 2004) e, em parte, na Terminologia (BARROS, 2004). Notamos
\end{abstract}

\footnotetext{
* Possui Graduação em Ciências Sociais com ênfase em Ciência Política pela Universidade Federal de São Carlos (2004) e Graduação Letras com Habilitação em Tradução pela Universidade Estadual Paulista (2009). Mestre em Estudos da Tradução pelo Programa de Pós-Graduação em Estudos Linguísticos da mesma Instituição. São Jose do Rio Preto, São Paulo, Brasil. E-mail: talitasrp82@gmail.com

** Doutorado em Tradução pela Universidade de São Paulo (1993), Pós-doutorado em Estudos da Tradução por The University of Manchester (2003), Livre-Docência em Estudos da Tradução pela Universidade Estadual Paulista Júlio de Mesquita Filho (2005). Atualmente é Professora Adjunta-MS5, aposentada da Universidade Estadual Paulista Júlio de Mesquita Filho, câmpus de São José do Rio Preto, onde atua como Professor Voluntário e faz parte do corpo de docentes permanentes dos Programas de Pós-Graduação em Letras e Estudos Linguísticos. São Jose do Rio Preto, São Paulo, Brasil. E-mail: divaccamargo@gmail.com
} 
que os termos empregados não apresentam univocidade dentro da linguagem da Antropologia Brasileira. Os termos traduzidos também refletem variação cultural devido às opções adotadas pelos tradutores para as possibilidades da Língua Meta.

Palavras-chave: Estudos da Tradução Baseados em Corpus. Linguística de Corpus. Antropologia Brasileira

\title{
DAMATTA AND RIBEIRO: SIMILARITIES AND DIFFERENCES IN TRANSLATION INTO ENGLISH OF TERMS AND EXPRESSION OF ANTHROPOLOGY SUBAREA IN THE WORKS CARNIVALS, ROGUES AND HEROES AND THE BRAZILIAN PEOPLE
}

\begin{abstract}
This study analyses the process of translating into English terms and expressions in the works written respectively by the anthropologists Roberto Da Matta and Darcy Ribeiro and in their respective translation. Our research project draws on Corpus-Based Translation Studies (BAKER, 1995, 1996, 2000; CAMARGO, 2007), Corpus Linguistics (BERBER SARDINHA, 2004) and on some concepts of Terminology (BARROS, 2004). Results show that the terms do not present univocity within the language related to Brazilian Anthropology. The translated terms also reflect a cultural change due to the options chosen by the respective translators for the target language possibilities.
\end{abstract}

Keywords: Corpus-Based Translation Studies. Corpus Linguistic. Brazilian Anthropology.

O desenvolvimento da pesquisa antropológica no Brasil fundamentou-se no pressuposto da consolidação de um objeto de análise que fosse puramente nacional. Investigações anteriores marcavam-se pelos relatos históricos de grupos colonizadores e pelo eurocentrismo que regrava e promovia a domesticação teórica. Na contramão dos modelos de pesquisa importados, autores como DaMatta e Ribeiro promoveram o estudo do Brasil como sociedade e sistema cultural independentes. 
Ribeiro (1995, p. 13) salienta que:

[...] nos faltava uma teoria geral, cuja luz nos tornasse explicáveis em seus próprios termos, fundida em nossa experiência histórica. As teorizações oriundas de outros contextos eram todas elas eurocêntricas demais e, por isso mesmo, impotentes para nos fazer inteligíveis. Nosso passado, não tendo sido o alheio, nosso presente não era necessariamente o passado deles, nem nosso futuro um futuro comum.

DaMatta, por sua vez, desenvolve a observação de rituais e festivais brasileiros, tendo como foco a composição estrutural do futebol, música, comida, carnaval, mulher, morte, jogo de bicho e categorias de tempo e espaço.

Por meio de focos analíticos distintos, ambos os pesquisadores procuram desenvolver um processo de consolidação das bases de compreensão da sociedade nacional via Antropologia. Dessa forma, mediante abordagens que valorizam as relações sociais da maior nação latino-americana e que promovem uma teoria baseada nos processos culturais do Brasil, a tradução, na direção português $\rightarrow$ inglês, desta nova teorização faz-se necessária, com o objetivo de proporcionar a divulgação dos trabalhos de DaMatta e Ribeiro em nível internacional, elevando a categoria da produção científica de antropólogos brasileiros fora do país.

No entanto, ainda são inexistentes investigações sobre o uso de termos e expressões mais frequentes encontrados nas obras Carnavais, Malandros e Heróis: para uma sociologia do dilema brasileiro (RIBEIRO, 1979) e O povo brasileiro: formação e sentido do Brasil (RIBEIRO, 1995), evidenciando a necessidade de observar a natureza deste tipo de texto de especialidade, assim como da tradução de termos e expressões presentes em ambas as obras.

Por tal razão, utilizamo-nos das teorias propostas para os Estudos da Tradução Baseados em Corpus (BAKER, 1995, 1996, 2000; CAMARGO, 2005) e para a Linguística de Corpus (BER- 
BER SARDINHA, 2004), a fim de verificar as escolhas lexicais feitas por John Drury e Gregory Rabassa nas respectivas traduções Carnivals, Rogues and heroes: an interpretation of the brazilian dilemma (1991) e The Brazilian People: formation and meaning of Brazil (2000) e também buscamos investigar as tendências linguísticas apresentadas por estes tradutores no que concerne aos termos e expressões que descrevem a sociedade brasileira, enfatizando as relações de significado que se estabelecem entre as teorias das obras, por meio do léxico, e as dissociações de conceitos ocorrentes no ato tradutório.

\section{Fundamentação Teórica}

Ao propor a abordagem teórico-metodológica para os Estudos da Tradução Baseados em Corpus, Baker (1995, 1996, 2000) assume uma posição de liderança na área. Para desenvolver seu trabalho, a teórica fundamenta-se nos Estudos Descritivos da Tradução, com base nos trabalhos de Even-Zohar (1978) e de Toury (1978). A autora também se apoia nas investigações de Sinclair (1991), no tocante ao aporte teórico da Linguística de Corpus e ao uso de corpora eletrônicos e ferramentas computacionais para a realização de pesquisas nos textos meta (TMs).

Baker (1995, p. 226) apresenta sua concepção de corpus na qual explicita a preferência pela análise por meio de computador:

[...] corpus é um conjunto de textos naturais (em oposição a exemplos/sentenças), organizados em formato eletrônico, passíveis de serem analisados, preferencialmente, em forma automática ou semi-automática (em vez de manualmente). ${ }^{1}$

Dessa forma, o consenso no uso de corpora para a investigação em tradução contribui para que autores como Tymoczko (1998) destaquem como principais vantagens para as análises 
na área: a) a integração de abordagens linguísticas e de estudos culturais à tradução; b) a obtenção de resultados teóricos e práticos; c) o potencial de se investigar as particularidades de fenômenos específicos da linguagem; d) a flexibilidade e adaptabilidade dos corpora.

A Linguística de Corpus, por sua vez, caracteriza-se por seu caráter transdisciplinar e pela possibilidade de análise de grandes quantidades de informações. Fundamenta-se a partir de uma base empirista e considera a linguagem como um sistema probabilístico. Para Berber-Sardinha (2004, p. 30):

[...] a visão da linguagem como sistema probabilístico pressupõe que, embora muitos traços linguísticos sejam possíveis teoricamente, não ocorrem com a mesma frequência.

Compreendemos, com isso, que a linguagem apresenta dada regularidade, o que permite que seja mapeada de acordo com o contexto de uso. Dessa forma, no âmbito da tradução, é possível delinear, por meio da análise de corpora, quais os traços mais recorrentes no processo de transposição de uma língua à outra. Isso significaria dizer que, como afirma Berber-Sardinha (2004, p. 31), a linguagem é padronizada e não um conjunto de escolhas aleatórias de indivíduos isolados.

Em complementação a essas teorias, o presente trabalho também faz uso de pressupostos da Terminologia. Assim, o tradutor que se dedica a uma área de especialidade inevitavelmente utiliza em seu trabalho termos específicos e a linguagem adequada ao campo escolhido. A Terminologia fornece, pois, o material necessário à tradução para o acesso rápido aos termos apropriados da área.

De acordo com Barros (2004), a definição de "termos" caracteriza-se por designar conceitos específicos de um domínio de especialidade. Quanto às “expressões fixas”, para Baker (1992), tratam-se de expressões consagradas, referentes a determinado tipo de texto, e que permitem pouca ou nenhuma variação. No caso das expressões 
semifixas, Camargo (2005) aponta que apresentam maiores variações e carregam consigo todo um contexto, podendo ser consideradas especificas de uma determinada língua de especialidade.

No âmbito da construção terminológica na área das Ciências Sociais, Pathak (1998) acrescenta determinados aspectos condicionantes que diferem das demais áreas de especialidade. São eles: (1) o fato de que nesta área diversos termos podem designar um mesmo conceito; (2) um mesmo termo pode designar diferentes conceitos; (3) diferentes estudiosos associam conceitos distintos a um único termo; (4) os conceitos são geralmente expressos por palavras de uso cotidiano; e (5) em Ciências Sociais os termos não são formulados em linguagem simbólica.

Para Barros (2004), os povos recortam a realidade de maneiras diferenciadas e as conceituações das representações sociais são designadas por unidades lexicais que, consideradas como signos de domínios específicos da atividade da comunidade sociocultural, podem ser afirmadas como unidades terminológicas. Verifica-se que cada antropólogo delimita seu campo de estudo e procura conceber nomeações para seus objetos de análise. Temos, por conseguinte, que as subáreas das Ciências Sociais apresentam um vocabulário especializado com a criação de conceitos teóricos que assumem características próprias dentro da obra de cada pesquisador.

No caso das pesquisas realizadas no Brasil, podemos considerar esses fatores como brasileirismos, os quais, de acordo com Coelho (2003), podem ser compreendidos como índices linguísticos da identidade do povo brasileiro. Para Faulstich (2004), algumas dessas entidades linguístico-culturais assumem um quadro conceitual que é mais de natureza terminológica do que de linguagem comum, compondo os chamados brasileirismos terminológicos. Admite-se que estas unidades lexicais constituem um caráter funcional em contextos científicos específicos. A teórica define os brasileirismos terminológicos como "palavras, locuções e outra estrutura sintagmática criada e formada no Brasil, que tenha significado autônomo e esteja encerrado num conceito de especialidade, que possibilite reconhecer a área a que pertence" (FAULSTICH, 2004). 
O processo tradutório de tal repertório terminológico, segundo Heim \& Tymowski (2006), segue algumas diretrizes metodológicas, visto que os textos das áreas antropológica, sociológica, etc. são distintos dos demais textos científicos por não poderem ser generalizados e estarem submetidos a contextos sociais, políticos e culturais distintos, de acordo com o país e as tradições e costumes que os constituem. Embora afirmem que essa submissão a fatores sociais específicos de determinadas culturas gere inconsistência terminológica, os autores observam que:

Um termo-chave que ocorre mais de uma vez pode ser traduzido pela mesma palavra sempre, mas o tradutor precisa primeiramente determinar se o significado é de fato o mesmo. Se não for, o tradutor pode escolher outra palavra, mas a decisão deve ser consciente. Para estabelecer consistência na tradução, o editor pode sugerir que os tradutores elaborem um glossário de termos-chave quando trabalham com um texto específico² (HEIM \& TYMOWSKI, 2006, p. 10).

Os cientistas sociais, ao introduzirem novos conceitos, geralmente atuam para que as palavras ou expressões empregadas sejam aceitas pela comunidade científica e se universalizem dentro desse público, passando a constituir termos. Os conceitos que transmitem são, em geral, socialmente determinados, mas a opção por termos técnicos também é um aspecto dessas ciências, solicitando dos tradutores especial atenção no momento de vertê-los para as Línguas Metas (LMs).

Tendo por base tais questões, apresentamos uma análise da tradução de termos e expressões socialmente marcados recorrentes nas obras de ambos os autores, observando as semelhanças e diferenças de opções utilizadas pelos tradutores na tentativa de transmitir ao público alvo conceituações encontradas nas duas obras.

Para a extração dos termos em seus cotextos, foram utilizadas as ferramentas WordList, Keywords e Concord do programa computa- 
cional WordSmith Tools. Dessa forma, consideramos ser possível para o tradutor e para o usuário de linguagens de especialidade, nesse caso das Ciências Sociais, familiarizarem-se com termos e expressões dessa natureza a fim de produzir ou traduzir textos culturalmente marcados com consciência e adequação terminológica.

\section{Material e Método}

Para esta investigação, foram compilados os seguintes corpora: 1) um subcorpus principal paralelo de Antropologia, constituído pela obra científica Carnavais, malandros e heróis: para uma sociologia do dilema brasileiro, de autoria de Roberto DaMatta, publicada originalmente em português, no ano de 1971 (total de itens: 104.893) e pela respectiva tradução para o inglês, realizada por John Drury, sob o título Carnivals, Rogues and Heroes: An Interpretation of the Brazilian Dilemma, no ano de 1991 (total de itens: 115.765); 2) um subcorpus principal paralelo constituído pela obra $O$ povo brasileiro: a formação e o sentido do Brasil, de autoria de Darcy Ribeiro, publicada originalmente em português, no ano de 1995 (total de itens: 115.474), e pela respectiva tradução para o inglês, realizada por Gregory Rabassa, sob o título The Brazilian People: Formation and Meaning of Brazil, publicada em 2000 (total de itens: 139.858).

Também utilizamos dois corpora de referência para a extração de palavras-chave, ou seja, palavras cuja frequência no corpus de estudo é estatisticamente significante se comparada à frequência da mesma palavra em um corpus de referência (corpus de língua geral pelo menos cinco vezes maior que o corpus de estudo). Em português, utilizamos o corpus Lácio-Ref, composto de textos em português brasileiro. Para a extração de palavras-chave em inglês, empregamos como corpus de referência British National Corpus (BNC Sampler), composto por textos originalmente escritos em inglês. 


\section{Análise e Discussão dos Resultados}

O levantamento dos termos e expressões de Antropologia nas obras dos subcorpora de estudo em língua fonte (LF) e em LM foi realizado por meio da seleção dos vocábulos mais representativos de base substantival e adjetival com fundamento no critério de maior chavicidade ${ }^{3}$.

\subsection{Análise da frequência e das palavras-chave nas quatro obras do corpus de estudo}

A análise dos subcorpora de estudo da obra Carnavais, $M a-$ landros e Heróis e da respectiva tradução Carnivals, Rogues and Heroes realizou-se por meio das listas de frequência de palavras extraídas com o auxílio da ferramenta WordList. Apresentamos, abaixo, as Tabelas 1 e $2 \mathrm{com}$ as dez palavras mais frequentes no texto fonte (TF) e no TM.

\begin{tabular}{l|l|l}
\hline 1. Social (617) & 5. Indivíduo (168) & 9. Ritual (121) \\
2. Carnaval (346) & 6. Poder (163) & 10. Universo (101) \\
3. Sociedade (320) & 7. Casa (156) & \\
4. Pessoas (180) & 8. Trabalho (142) & \\
\hline
\end{tabular}

Tabela 1- Lista das dez palavras mais frequentes no subcorpus de estudo da obra Carnavais, Malandros e Heróis

\begin{tabular}{l|l|l}
\hline 1. Social (965) & 5. Individual (220) & 9. Work (106) \\
2. Society (358) & 6. Person (182) & 10. Human (100) \\
3. People (233) & 7. Power (147) & \\
4. Ritual (226) & 8. House (122) & \\
\hline
\end{tabular}

Tabela 2 - Lista das dez palavras mais frequentes no subcorpus de estudo da obra Carnivals, Rogues and Heroes

Das palavras presentes na Tabela 1, oito encontraram equivalentes na Tabela 2: "social" $\rightarrow$ social; "sociedade" $\rightarrow$ society; "pesso- 
as" $\rightarrow$ people; "indivíduo" $\rightarrow$ individual; "poder" $\rightarrow$ power; "casa" $\rightarrow$ house; "trabalho" $\rightarrow$ work e "ritual" $\rightarrow$ ritual. As outras duas palavras que não constaram entre as dez primeiras ("carnaval" $\rightarrow$ carnival e "universo" $\rightarrow$ universe) apareceram entre as cem palavras mais frequentes na lista de palavras do subcorpus do TM.

Com o auxílio da ferramenta KeyWords, foram geradas as listas de palavras-chave do subcorpus do TF, tomando para contraste o corpus de referência Lácio-Ref. Após este levantamento, foram também observadas as palavras-chave a partir do TM, tendo como corpus de referência o BNC Sampler. Abaixo, apresentamos as Tabelas 3 e 4 com as respectivas dez palavras-chave de maior índice:

\begin{tabular}{l|l|l}
\hline 1. Pessoa (133) & 5. Hierarquia (77) & 9. Vingança (64) \\
2. Ritual (121) & 6. Ideologia (75) & 10. Herói (63) \\
3. Samba (95) & 7. Rito (71) & \\
4. Sociedades (90) & 8. Fazendeiro (69) & \\
\hline
\end{tabular}

Tabela 3 - Lista das dez palavras-chave a partir do subcorpus de estudo da obra Carnavais, Malandros e Heróis

\begin{tabular}{l|l|l}
\hline 1. Samba (117) & 5. Hierarchy (97) & 9. Rituals (73) \\
2. Societies (113) & 6. Rules (93) & 10. Vengeance (60) \\
3. Persons (99) & 7.Domain (76) & \\
4. Laws (98) & 8. Ideology (74) & \\
\hline
\end{tabular}

Tabela 4 - Lista das dez palavras-chave a partir do subcorpus de estudo da obra Carnivals, Rogues and Heroes

Para dar suporte à seleção de tais dados, realizou-se uma consulta a um corpus de apoio formado por dicionários das subáreas das Ciências Sociais, a saber: Antropologia, Ciência Política, Economia e Sociologia para abonar sua inclusão ou exclusão nas nossas análises. A observação da frequência dos itens lexicais da obra de DaMatta (Tabela 1) e de sua tradução (Tabela 2) permite reconhecer quais os principais assuntos abordados pelo autor, que se refere aos comportamentos culturais e folclóricos brasileiros, o 
que lhe permite traçar um panorama geral das relações socioeconômicas da Sociedade Brasileira. Notamos, também, que o tradutor Drury manteve a frequência de palavras semelhante à de DaMatta, trazendo apenas duas palavras mais recorrentes que o autor: person e human. Os dados permitem observar a relevância da formação do indivíduo e sua integração com a formação do conceito de humanidade proposto pelo autor e enfatizado pelo tradutor.

Similarmente, realizamos investigações para os subcorpora da obra O povo brasileiro (RIBEIRO, 1995) e da respectiva tradução The Brazilian People (2000). Abaixo, apresentamos as Tabelas de 5 a 8 com as dez palavras mais frequentes e as dez palavras-chave do TF e do TM.

\begin{tabular}{l|l|l}
\hline 1. Índios (446) & 5. Sociedade (167) & 9. Economia (134) \\
2. População (246) & 6. Negros (164) & 10. Civilização (123) \\
3. Terra (203) & 7. Povo (144) & \\
4. Social (174) & 8. Escravos (138) & \\
\hline
\end{tabular}

Tabela 5 - Lista das dez palavras mais frequentes no subcorpus de estudo da obra o povo brasileiro

\begin{tabular}{l|l|l}
\hline 1. Indians (469) & 5. Social (208) & 9. Blacks (168) \\
2. People (464) & 6. Society (187) & 10. Indian (157) \\
3. Land (265) & 7. Work (178) & \\
4. Population (265) & 8. Slaves (177) & \\
\hline
\end{tabular}

Tabela 6 - Lista das dez palavras mais frequentes no subcorpus de estudo da obra The Brazilian People

\begin{tabular}{l|l|l} 
1. Terras (512) & 5. Negros (149) & 9. Civilização (112) \\
2. Índios (386) & 6. Povo (130) & 10. Cultural (110) \\
3. População (240) & 7. Gente (134) & \\
4. Sociedade (158) & 8. Economia (121) & \\
\hline
\end{tabular}

Tabela 7- Lista das dez palavras-chave a partir do subcorpus de estudo da obra O povo brasileiro 


\begin{tabular}{l|l|l}
\hline 1. Indians (469) & 5. Social (208) & 9. Indian (157) \\
2. People (464) & 6. Society (187) & 10. Economy (130) \\
3. Land (265) & 7. Slaves (177) & \\
4. Population (265) & 8. Blacks (168) & \\
\hline
\end{tabular}

Tabela 8 - Lista das dez palavras-chave a partir do subcorpus de estudo da obra The Brazilian People

Notamos que as listas de palavras-chave destacaram a representatividade dos dois pares de obras (Carnavais, Malandros e Heróis/ $O$ povo brasileiro) uma vez que apresentam as palavras de maior chavicidade em contraste com um corpus de referência de mais de um milhão de palavras. Esses índices de chavicidade apontam um uso frequente de palavras que poderiam ser consideradas fortes candidatos a termos na subárea de Antropologia. Ao cruzarmos as listas das Tabelas 3 e 7 dos respectivos TFs, observarmos que somente o termo geral das Ciências Sociais: "sociedade" $\rightarrow$ society é comum a ambas as obras. Os dados mostram que os tradutores optaram por algumas escolhas léxicas distintas ao levar as teorias brasileiras para o público alvo. Tais resultados salientam a validade de um levantamento de termos com a metodologia da Linguística de Corpus, dado que auxiliaram no refinamento das listas apresentadas neste trabalho, as quais poderão auxiliar o tradutor ao lidar com textos específicos de Ciências Sociais.

\subsection{Análise da tradução de termos simples, expressões fixas e} semifixas mais frequentes nos pares de obras do corpus de estudo

As palavras-chave selecionadas a partir dos subcorpora principais dos TFs foram comparadas às palavras-chave extraídas a partir dos respectivos TMs. A investigação dos termos mais frequentes permitiu constatar que, em grande parte, as palavras-chave dos subcorpora principais em LM coincidiam com as palavras-chave de LF em ambas as obras. 
Com base nesses dados, apresentamos, abaixo, as Tabelas 9 e 10 com os dez primeiros candidatos a termos simples mais frequentes nos TFs e as respectivas traduções, extraídos dos subcorpora paralelos de cada par de obras da subárea de Antropologia:

\begin{tabular}{l|l}
\hline TF & TM \\
\hline 1. Pessoa & 1. Person \\
2. Ritual & 2. Ritual \\
3. Samba & 3. Samba \\
4. Sociedades & 4. Societies \\
5. Hierarquia & 5. Hierarchy \\
6. Ideologia & 6. Ideology \\
7. Rito & 7. Rite \\
8. Fazendeiro & 8. Master \\
9. Vingança & 9. Vengeance \\
10. Herói & 10. Hero \\
\hline
\end{tabular}

Tabela 9 - Dez candidatos a termos simples mais frequentes no TF da obra Carnavais, Malandros e Heróis e respectivas traduções no TM

\begin{tabular}{l|l}
\hline $\mathrm{TF}$ & $\mathrm{TM}$ \\
\hline 1.Terras & 1. Lands \\
2. Índios & 2. Indians \\
3. População & 3. Population \\
\hline 4. Sociedade & 4. Society \\
5. Negros & 5. Blacks/Negroes \\
6. Povo & 6. People \\
7. Gente & 7. People \\
8. Economia & 8. Economy \\
9. Civilização & 9. Civilization \\
10. Cultural & 10. Cultural \\
\hline
\end{tabular}

Tabela 10 - Dez candidatos a termos simples mais frequentes no TF da obra $O$ povo brasileiro e respectivas traduções no TM 
Foi possível notar que o processo de análise das palavras mais frequentes das obras revela algumas recorrências no uso de termos simples, o que evidencia que tanto DaMatta quanto Ribeiro desenvolveram estudos cujas teorias fundamentam-se em objetos semelhantes, como a relação entre personagens sociais em dados territórios, por exemplo, "fazendeiro" e "trabalhador" no ambiente das grandes propriedades.

A partir das palavras-chave levantadas em língua portuguesa (Tabelas 3 e 7), realizamos a observação das linhas de concordância, dos agrupamentos lexicais e dos colocados por meio da ferramenta Concord. Abaixo, apresentamos nas Tabelas 11 e 12, três dos candidatos a termos mais frequentes em ambos os TFs e as expressões por eles formadas ("sociedade/s", "tribal/is" e "social/is"):

SOCIEDADE/S - Sociedade Civil - Sociedade Humana- Sociedades Individualistas - Sociedades Tradicionais - Sociedades Tribais Sociedades Holísticas - Sociedades Semitradicionais - Sociedades Aristocráticas - Sociedade Paralela - Sociedade Complexa

- Sociedades Igualitárias - Sociedade Dominante - Sociedade Carnavalesca

TRIBAL/IS - Grupos Tribais - Sistemas Tribais - Canções Tribais Mundo Tribal - Mito Tribal

SOCIAL/IS - Exploração Social - Sistema Social - Domínios Sociais

- Processos Sociais - Igualdade Social - Mundo Social - Bandido

Social - Formações Sociais - Relações Sociais - Relacionamento

Social - Apadrinhamento Social - Mediadores Sociais - Totalidade

Social - Segmentação Social - Comportamento Social - Mudança

Social - Papéis Sociais - Identidade Social - Ideologias Sociais Estratificação Social - Classificação Social - Banditismo Social Ordem Social - Nirvana Social - Hierarquia Social - Classes Sociais

- Hierarquização Social - Fato Social - Moralidade Social

Tabela 11 - Candidatos a termos simples e expressões fixas e semifixas extraídos do subcorpus principal da obra Carnavais, Malandros e Heróis 
SOCIEDADE/S - Sociedade Parasitária - Sociedade Nascente Sociedade Brasileira - Sociedades Tribais - Sociedades Tribais Autônomas - Sociedade Cabocla - Sociedade Colonial - Sociedade Agrária - Sociedade Rural - Sociedade Sertaneja - Sociedade Solidária - Sociedade Subalterna - Sociedade Democrática Sociedade Multiétnica - Sociedade Igualitária - Sociedades Nacionais

TRIBAL/IS - Índios Tribais - Cultura Tribal - Organizações Tribais - Vida Tribal - Territórios Tribais - Aldeia Tribal - Identidade Tribal - Grupos Tribais - Grupos Tribais Livres - Mundo Tribal - Mundo Tribal Igualitário - Etnias Tribais - Microetnias Tribais Negro Tribal - Ancestrais Tribais - Populações Tribais - Populações Tribais Autônomas - Depopulação Tribal - Africanos Tribais Identificação Tribal

SOCIAL/IS - Ordem Social - Papel Social - Responsabilidades Sociais - Convívio Social - Reformador Social - Consciência Social - Preconceito Social - Vida Social - Função Social - Estratos Sociais - Classes Sociais - Estratificação Social - Miopia Social - Antagonismos Sociais - Ascensão Social - Revolução Social Democracia Social - Convivência Social

Tabela 12 - Candidatos a termos simples e expressões fixas e semifixas extraídos do subcorpus principal da obra $O$ povo brasileiro

Observamos que algumas das expressões mais frequentes estão presentes nos TFs de ambas as obras. Como as opções de tradução de Drury e Rabassa apresentam algumas vezes similaridades e outras vezes diferenças, montamos a Tabela 13, abaixo, para ilustrar as coocorrências:

\begin{tabular}{l|l|l}
\hline $\begin{array}{l}\text { Expressões Fixas e } \\
\text { Semifixas Coocorrentes } \\
\text { nas duas obras em LF }\end{array}$ & $\begin{array}{l}\text { Tradução de } \\
\text { John Drury }\end{array}$ & $\begin{array}{l}\text { Tradução de } \\
\text { Gregory Rabassa }\end{array}$ \\
\hline Sociedade/s Tribal/is & Tribal Society/ies & Tribal Society/ies \\
\hline Sociedade/s Igualitária/s & $\begin{array}{l}\text { Egalitarian Society/ } \\
\text { ies }\end{array}$ & $\begin{array}{l}\text { Egalitarian Society/ } \\
\text { ies }\end{array}$ \\
\hline
\end{tabular}




\begin{tabular}{l|l|l}
\hline Grupo/s Tribal/is & Tribal Group/s & $\begin{array}{l}\text { Tribal Group/s } \\
\text { Tribal Grouping/s }\end{array}$ \\
\hline Mundo/s Tribal/is & Tribal World/s & Tribal World/s \\
\hline Formação/ões Tribal/is & Tribal Formation/s & Tribal Formation/s \\
\hline Relação/ões Social/is & Social Relation/s & Social Relation/s \\
\hline Estratificação Social & Social Stratification & Social Stratification \\
\hline Classe/s Social/is & Social Class/es & Social Class/es \\
\hline Estrutura/s Social/is & Social Structure/s & Social Structure/s \\
\hline Convivência Social & Shared Social Life & Social Environment \\
\hline
\end{tabular}

Tabela 13 - Expressões Fixas e Semifixas Coocorrentes em Carnavais, Malandros e Heróis e em $O$ povo brasileiro que apresentam algumas variações nas opções de tradução nos corpora dos TMs

Os dados mostram que dez expressões ocorrem com maior frequência nos dois pares de obras. Com base na Tabela acima, podemos observar que a maior parte das expressões coocorrentes nos TFs apresenta as mesmas opções de tradução nos respectivos TMs. Por outro lado, na tradução das expressões grupo/s tribal/ is e convivio social, Drury escolheu as seguintes opções: tribal group/s e shared social life, ao passo que Rabassa optou por: tribal grouping/s e social environment. No entanto, a maior das expressões apresenta regularidade concernente às Ciências Sociais e as suas subáreas.

É interessante notar que as variações representam mais que simples alternâncias lexicais. Os comportamentos tradutórios de Drury e Rabassa refletem as relações teóricas contidas nas obras de DaMatta e de Ribeiro, respectivamente, uma vez que parecem mostrar como os tradutores depreendem os significados contidos nas expressões e reconstroem a proposta analítica de interpretação do "povo brasileiro". 
Do mesmo modo, encontramos termos simples de maior chavicidade na obra Carnavais, Malandros e Heróis, de DaMatta, que também aparecem na obra $O$ povo brasileiro, de Ribeiro. Com isso, verificamos se as escolhas lexicais de Drury poderiam fornecer diferentes opções de tradução para os termos e expressões de Antropologia em relação às estratégias utilizadas por Rabassa no processo tradutório da mesma subárea.

\begin{tabular}{|c|c|c|}
\hline $\begin{array}{l}\text { Termos Simples } \\
\text { Coocorrentes nas } \\
\text { obras do subcorpus } \\
\text { de estudo em LF }\end{array}$ & $\begin{array}{l}\text { Tradução de John } \\
\text { Drury }\end{array}$ & $\begin{array}{l}\text { Tradução de } \\
\text { Gregory Rabassa }\end{array}$ \\
\hline Cangaço & $\begin{array}{l}\text { Backwood/s } \\
\text { No man's Land/s }\end{array}$ & $\begin{array}{l}\text { Cangaço } \\
\text { Banditry }\end{array}$ \\
\hline Capanga/s & $\begin{array}{l}\text { Henchman/men } \\
\text { Man/men belonging } \\
\text { to }\end{array}$ & Capanga/s \\
\hline Caudilho/s & Political Boss/es & $\begin{array}{l}\text { Leader/s } \\
\text { Military Chieftain/s } \\
\text { Political Leader/s }\end{array}$ \\
\hline Fazenda/s & Ranch/es & Plantation/s \\
\hline Jagunço/s & $\begin{array}{l}\text { Bandit/s } \\
\text { Follower/s } \\
\text { Bandit Leader/s }\end{array}$ & $\begin{array}{l}\text { Jagunço/s } \\
\text { Thug/s }\end{array}$ \\
\hline
\end{tabular}

Tabela 14 - Termos Simples de maior chavicidade coocorrentes nas obras do subcorpus de TFs e variações nas suas traduções no subcorpus de TMs

Neste âmbito, podemos observar, por exemplo, o termo "jagunço”, o qual, para Ferreira, no Novo dicionário da língua portuguesa (1975), caracteriza um elemento social do nordeste, comparado ao "cabra", ao "capanga" e ao "chuço". 
É importante salientar que o termo apresenta diversos sentidos, os quais vão se adequando ao tempo e ao espaço. Com a campanha de Canudos, os seguidores de Antônio Conselheiro foram denominados "jagunços", e o termo adquiriu uma dimensão nacional e um novo sentido, ou seja, o de indivíduo que guerreia em defesa de um líder religioso carismático, recebendo em troca recompensa espiritual, um lugar no reino de Deus.

O fim dos movimentos político-religiosos no Brasil levou a constituição de uma nova significação para o termo: a de "capanga". Passaram a representar os homens que lutam em prol de um chefe de parentela ou político local (coronel), por sentimento de lealdade ou dívida e favor.

Observamos que, na maioria dos casos que constituem brasileirismos, Rabassa optou por realizar empréstimo, apresentando ao público de antropólogos estrangeiros todas as possíveis nuances de sentido do termo em LF. Contudo, a fim de alcançar a compreensão mais próxima à significação do TF, o tradutor escolhe vocábulos da língua geral, como no presente exemplo, thug, para explicitar a situação de uso de uma forma generalizada e simplificada.

No Oxford English Dictionary (1961), a definição de thug evidencia a formação de grupos de pessoas violentas, principalmente criminosos e bandidos. Estes agrupamentos seriam fraternidades secretas de assassinos e ladrões de viajantes, os quais apareceram, principalmente, na história da Índia. Registros indicam que se tornaram operantes no século XVI e que tiveram seu fim em meados do século XIX.

No entanto, Drury apresenta outras opções, como por exemplo, bandit e bandit leader, as quais se vinculam à ideia de banditry (banditismo). Esse termo caracteriza um tipo de deliquência comum às sociedades rurais de cultura tradicional e consiste no aparecimento de bandos armados que saqueiam, sequestram e assaltam viajantes, citadinos, representantes do Estado e das camadas mais altas da sociedade. Invadem vilas, povoados e cidades, mas evitam atacar comunidades rurais, as quais, muitas vezes, os ajudam e protegem, idealizando-os como heróis. 
Ao ligar a concepção de "jagunço" aos preceitos do termo banditry, o tradutor apresenta à Cultura Meta uma característica comum ao povo brasileiro, ou seja, a tendência que os grupos necessitados possuem de considerar os "malandros" ou "bandidos sociais" como salvadores e redentores dos padrões de cidadania nacional. Drury adequa-se à teorização de DaMatta e transpassa o papel de tradutor, adotando a postura de um defensor de novas relações sociais. O produto tradutório, Carnival, rogues and heroes, representa, para a sociedade de chegada, uma análise cultural dos antropólogos latinos que constituem a elite intelectual dos países antes oprimidos social e economicamente e que agora ganham voz perante o mundo globalizado.

Na obra em análise, notamos que o autor enaltece a estrutura de concepção dos núcleos socioculturais típicos do Brasil e, por conseguinte, debruça-se sobre a atuação de cada esfera e região, trabalhando muito mais com ambientes e seres sociais do território nacional.

Podemos depreender das escolhas de Drury e Rabassa que, como não antropólogos e cientistas sociais, os tradutores desenvolvem um comportamento inovador que se daria não apenas no ambiente da tradução, mas também em situações de adequação e análise de fatores sociais que são desconhecidos às comunidades de chegada.

Assim, por mais que o TM aproxime-se da teoria e do ideário temático contido no TF, em algumas situações a contextualização precisa abarcar a inserção de um novo conceito. As opções tradutórias constituem, neste quadro, uma maior aproximação ao contexto de situação do sistema social típico do Brasil.

Autor e tradutores agem como distintos atores sociais em ambientes humanos diferenciados por questões políticas e culturais que lhes são próprias, produzindo, com isso, textos com funções socioculturais independentes. No processo tradutório, o agente humano lida com elementos que podem interferir na interpretação e na concepção de conceitos entre os núcleos de antropólogos e pode gerar novas teorias e redefinições terminológicas. Ao nomear fenômenos culturais, 
o tradutor constitui-se, em parte, como um cientista social capaz de depreender da sociedade em que está inserido e da sociedade a qual observa, os valores necessários à elaboração de um conjunto léxico de especialidade adequado àqueles dois contextos.

\section{Considerações Finais}

Pudemos verificar que as ferramentas do software WordSmith Tools facilitam a investigação de grandes quantidade de dados, obtidos por processamento computacional com maior rapidez e precisão que manualmente. As linhas de concordância esclarecem dúvidas e fornecem o cotexto dos termos e expressões levantados, permitindo-nos observar a organização das palavras dentro dos sintagmas. Dessa forma, na subárea de Antropologia, notamos que a maioria dos termos e expressões levantados se inter-relacionam, gerando sentidos específicos de acordo com os contextos sócio-políticos e culturais da sociedade brasileira.

A consulta ao corpus de apoio mostra-se essencial para estudos desta natureza. Alguns termos e expressões levantados nos corpora principais, respectivamente utilizados pelos tradutores em questão, apresentam possibilidades de diferentes correspondências em inglês, como por exemplo: "vilarejo" que apresentou três correspondentes: village, hamlet e settlement. A escolha dos tradutores por variar o uso de diferentes escolhas lexicais representa a tentativa de mostrar ao público alvo a versatilidade da sociedade brasileira.

Devido à boa parte dos termos e expressões analisados não constar em dicionários especializados, a busca por correspondentes traz dificuldade para o tradutor que poderá encontrar estratégias para expressar a sociedade brasileira para a cultura de chegada. Neste sentido, evidencia-se a validade de glossários de termos simples e expressões fixas e semifixas mais frequentes na subárea das Ciências Sociais, como a amostra que foi proposta no presente trabalho.

Por fim, salientamos que o tradutor, ao trabalhar obras e textos de antropólogos e cientistas sociais precisa estar consciente do 
impacto de suas escolhas lexicais na teoria e na formação de um comportamento científico dos leitores da cultura de chegada. A variação terminológica, nesse contexto, atua não somente dentro do plano linguístico, mas perpassa as relações conceituais e age no plano do sentido e da formação do arcabouço terminológico e teórico dos antropólogos. Por tal razão, não basta ao tradutor fazer uma opção lexical adequada, as relações sociais implícitas terão influência no contexto extralinguístico, causando alterações de conduta e de leitura teórica e movimentando positiva ou negativamente a produção intelectual da Antropologia.

Acreditamos que este estudo comparativo possa oferecer uma contribuição para os Estudos da Tradução Baseados em Corpus e para a Linguística de Corpus. Esperamos também que esta investigação forneça subsídios a professores, pesquisadores, tradutores, alunos de tradução, bem como profissionais da área de Antropologia da Civilização, Antropologia Cultura, Antropologia Social e Ciências Sociais.

\section{Notas}

1. [...]corpus mean[s]any collection of running texts (as opposed to examples/ sentences), held in electronic form and analysable automatically or semi-automatically (rather than manually).

2. [...] a key term that occurs more than once should be translated by the same word each time, but the translator must first determine whether the meaning is in fact the same. If it is not, the translator may choose another word, but the decision must be a conscious one. To foster consistency, the editor can suggest that translators create a personal glossary of key terms as they work through a text. 
3. Compreendemos por chavicidade a relação estatística entre a ocorrência de dada palavra em um corpus de estudo e a importância que assume para o léxico de uma área de especialidade.

\section{Referências}

BARROS, L. A. Curso básico de Terminologia. São Paulo: EDUSP, 2004.

BAKER, M. In other words: a coursebook on translation. Londres: Routledge, 1992.

. Corpora in translation studies: an overview and some suggestions for future research. Target, Amsterdam, v. 7, n. 2, p. 223-243, 1995.

. Corpus-based translation studies: the challenges that lie ahead. In: SOMERS, H. (Ed). Terminology, LSP and translation studies in language engineering: in honour of Juan C. Sager. Amsterdam: John Benjamins. 1996, p. 177-186.

. Towards a Methodology for investigation the style of literary translation. $\overline{\text { Target }}$, Amsterdã, v. 12, n. 2, p. 241-266, 2000.

BERBER SARDINHA, T. Lingüística de Corpus. Barueri, São Paulo: Manole, 2004.

CAMARGO, D. C. de. Padrões de estilo de tradutores: um estudo de semelhanças e diferenças em corpora de traduções literárias, especializadas e juramentadas. 512 f. Tese (Livre-Docência em Tradução) - Instituto de Biociências, Letras e Ciências Exatas - Unesp, Universidade Estadual Paulista, São José do Rio Preto, 2005.

COELHO, O. Léxico, Ideologia e a Historiografia Linguística do Século das Identidades. Revista Letras, n.61, p.153-166, Editora UFPR. Curitiba, 2003. 
DAMATTA, R. Carnavais, Malandros e Heróis: para uma sociologia do dilema brasileiro. 6.ed. Rio de Janeiro: Rocco,1997.

. Carnivals, Rogues and heroes: an interpretation of the brazilian dilemma.

1. ed. Traduzido por John Drury. Notre Dame/London: Notre Dame Press, 1991.

RIBEIRO, D. O povo brasileiro: a formação e o sentido do Brasil. São Paulo: Companhia das Letras, 1995.

. The Brazilian People: formation and meaning of Brazil, Translated by Gregory Rabassa. Gainesville: University Press of Florida, 2000.

DICIONÁRIO DE CIÊNCIAS SOCIAIS. Rio de Janeiro: Editora Fundação Getúlio Vargas, 1986.

EVEN-ZOHAR, I. The position of translated literature within the literary polisystem. In: HOLMES, J.; LAMBERT, J.; VAN DEN BROECK, R. (Ed.). Literature and translation. Leuven. 1978, p. 83-100, [Versão revisada em VENUTI, L. (Ed.). The translation studies reader. London/New York: Routledge. 2000, p.198-211]

FAULSTICH, E. Duas questões em discussão: o que são brasileirismos nos dicionários de Língua Portuguesa? Existem brasileirismo terminológicos? In: Jornada sobre "Variación Geolectal i Terminologia" Red Panlatina de Terminología Realiter/IULAterm/Institut Universitari de Linguística Aplicada. Barcelona, Espanha, 24 de novembro de 2004.

FERREIRA, A.B.H. Novo dicionário da língua portuguesa. 3.ed. Rio de Janeiro: Nova Fronteira, 1975.

HEIM, M. H.; TYMOWSKI, A.Guideliness for the Translation of Social Science Texts. Nova Iorque: American Council of Learned Societies, 2006.

KRIEGER, M. G.; FINATTO, M. J. B. 2004. Introdução à Terminologia: teoria e prática. São Paulo: Editora Contexto, 2004.

OXFORD ENGLISH DICTIONARY, Clarendon Press, 1961. 
PATHAK, L.P. Sociological Concepts and Terminology. New Delhi: Anmol Publications PVT.Ltda., 1998.

SINCLAIR, J. M. Corpus, concordance, collocation. Oxford: Oxford, 1991.

TOURY, G. The nature and role of norms in literary translation. In: HOLMES, J.; LAMBERT, J.; VAN DEN BROECK, R. (Ed.). Literature and translation. Leuven, 1978, p117-127. [Versão revisada em VENUTI, L. (Ed.). The translation studies reader. London/New York: Routledge, 2000, p. 192- 198].

Recebido em: 10/05/2015 Aceito em: 09/07/2015 